\title{
Cutting AISI 1045 steel at very high speeds
}

\author{
G.G. Ye ${ }^{\mathrm{a}, \mathrm{b}}$, S.F. Xue ${ }^{\mathrm{b}}$, W. Ma ${ }^{\mathrm{c}}$, M.Q. Jiang ${ }^{\mathrm{a}}$, Z. Ling ${ }^{\mathrm{a}}$, X.H. Tong ${ }^{\mathrm{b}}$, L.H. Dai ${ }^{\mathrm{a}, *}$ \\ a State Key Laboratory of Nonlinear Mechanics, Institute of Mechanics, Chinese Academy of Sciences, Beijing 100190, China \\ ${ }^{\mathrm{b}}$ Department of Engineering Mechanics, Petroleum University of China, Shandong 257061, China \\ ${ }^{c}$ Key Laboratory of Environmental Mechanics, Institute of Mechanics, Chinese Academy of Sciences, Beijing 100190, China
}

\section{A R T I C L E I N F O}

\section{Article history:}

Received 17 June 2011

Received in revised form

18 December 2011

Accepted 22 December 2011

Available online 30 December 2011

Keywords:

High speed machining

AISI 1045 steel

Chip formation

Surface integrity

Thermoplastic shear

\begin{abstract}
A B S T R A C T
An experimental device, based on the light-gas gun technology, was set up to realize high speed cutting over a wide range of cutting speeds from $30 \mathrm{~m} / \mathrm{s}$ to $200 \mathrm{~m} / \mathrm{s}$. High-speed cutting experiments were performed on AISI 1045 steels. The investigation of chip morphology, micro-structures, micro-hardness and the finished surface integrity were carried out, focusing on the physical phenomena accompanying the saw-tooth chip formation. The results reveal that, with increasing the cutting speed, the transition of chip morphology from continue to saw-tooth could be attributed to repeated thermoplastic shearbanding rather than periodic cracking. In particular, a severe material flow leading to mass transfer of heat was observed at very high cutting speed. The effect of mass transfer of heat on thermoplastic shear instability was further investigated, which implies that the mass transfer of heat would retard the formation of saw-tooth chip. Finally, the influence of cutting speed and mass transfer on the temperature distribution during high speed machining was briefly discussed.
\end{abstract}

(c) 2011 Elsevier Ltd. All rights reserved.

\section{Introduction}

High speed machining (HSM) has many advantages such as high removal rates, reduction in dead times and low cutting forces, leading to excellent dimensional accuracy and surface finishing quality [1]. Recently, HSM has been widely used in aerospace, automotive, die/mold-making and defense industries [2]. The concept of HSM was originally introduced by Salomon [3], which assumed that the cutting temperature decreases with increasing the cutting speed after it attains a peak for a certain critical value. HSM essentially is a highly nonlinear and coupled thermomechanical process, during which the workpiece materials ahead of the tool tip undergo large deformation, high strain rate, high temperature and complex friction. Such extreme conditions pose a big challenge to the fundamental understanding of the HSM process, which has received much attention [4-9]. In this aspect, areas of interest involve the feasibility of HSM [4,5], the mechanics of segmentation [6,7], the stability of adiabatic shear banding $[6,8]$, etc. Among them, the chip formation is of central importance since the chips are witnesses of physical and thermal phenomena happening during HSM [9]. For many materials, continuous chips are usually produced at a low cutting speed. As the cutting speed increases into HSM range however, the formed chips are prone to be

\footnotetext{
* Corresponding author. Tel.: +86 10 82543958; fax: +86 1082543977 .

E-mail address: lhdai@Inm.imech.ac.cn (L.H. Dai).
}

serrated or saw-tooth-like [8,9]. The saw-tooth chip formation ties up with decreased tool life, degradation of the workpiece surface finish and less accuracy in the machined part $[10,11]$. Hence, understanding of the cause and the initiation of saw-tooth chip formation could be of significant importance.

As for the saw-tooth chip formation, there have been two potential causes. The first suggests that the saw-tooth chips result from a repeated thermoplastic instability occurred within the primary shear zone (PSZ) [6,8,11-13]. This phenomenon takes place when the thermal softening caused by plastic work overcomes the work hardening of the material $[12,14]$. The second contends that the formation of saw-tooth chip can be attributed to a periodic crack initiated in the free surface of workpiece ahead of the tool [7,15-17]. These two different theories have long been controversial, and there have still been no definite conclusion about how the saw-tooth chip forms. Astakhov [18,19], SheikhAhmad et al. [20] and Barry and Byrne [14] have pointed out that the potential cause of the saw-tooth chip formation could be different between ductile materials and brittle ones: the saw-tooth chip formation tends to be formed from repeated shear bandings for ductile materials, but it is more likely to arise from periodic cracks as for brittle ones. However, the exact location of the border 'brittle/ductile' in metal cutting is hard to quantify [18], and the ductility of the workpiece material could change under the coupling condition of high strain rate and temperature during HSM [20]. Moreover, especially at an extremely high cutting speed, some factors, such as momentum diffusion, inertia and especially the mass transfer of heat induced by the rapid chip 
flow [21,22], could become significant. This makes the problem more complicated, and thus the mechanisms of saw-tooth chip formation at extremely high cutting speed deserve further investigation.

In order to get a better understanding of the cause for the sawtooth chip formation during HSM, it is urgent to develop proper experimental setups to simulate or directly investigate the cutting process at very high speed. In recent years, some apparatus have been developed to perform HSM studies. Kazban et al. [23] used the modified Hopkinson bar to simulate high speed orthogonal machining at $30 \mathrm{~m} / \mathrm{s}$ for an aluminum alloy, focusing on the cutting forces and temperature distribution around the tool tip. Sutter et al. [24] employed a ballistic set-up to obtain high cutting speeds, up to $100 \mathrm{~m} / \mathrm{s}$. By using this device, they investigated the evolution of chip segmentation when cutting a medium carbon steel with an uncut chip thickness of $0.3 \mathrm{~mm}$, and the saw-tooth chip was obtained at the cutting speed about $18 \mathrm{~m} / \mathrm{s}$. The measurements of cutting force and temperature were carried out in their latter work, and some important relationships between the chip geometry and the cutting conditions (cutting speed, uncut chip thickness and the rake angle) were established $[9,25]$. These experimental results provide useful clues for the understanding of the formation mechanism of chip, especially the cause for the saw-tooth chip formation at extremely high cutting speeds, which is the focus of the present work.

In this work, an experimental procedure based on a light-gas gun is developed to perform HSM in a wide range of velocities. With this developed experimental procedure, a typical medium carbon steel (AISI 1045 steel) is machined with the cutting speed ranging from $30.8 \mathrm{~m} / \mathrm{s}$ to $67.3 \mathrm{~m} / \mathrm{s}$. The microscopic characteristics of chips, such as the metallographic structure, grain deformation and the free surface morphology, are systematically investigated. It is observed that the formed chip transfers from continuous to sawtooth-like at a cutting speed up to $38 \mathrm{~m} / \mathrm{s}$, and the saw tooth chip formation could be attributed to repeated thermoplastic shearbanding rather than periodic cracking. Furthermore, the stability analysis of the PSZ was carried out, which reveals that the mass transfer of heat due to rapid chip flow retards the thermoplastic shear instability, and hence hinders the formation of sawtooth chip.

\section{Experimental setup}

\subsection{Device description}

The experimental machining device that is based on a light-gas gun is schematically presented in Fig. 1. This device allows real orthogonal cutting, under quasi-stationary conditions, with a maximum allowable velocity up to $200 \mathrm{~m} / \mathrm{s}$.

The cutting tool holder is fixed on a projectile, which is launched inside a tube by a light-gas gun. The cutting tool holder can accommodate cutting inserts typically used in industry. The projectile is guided in the launch tube to avoid any rotation. A sufficient length of the launch tube $(6 \mathrm{~m})$ allows the projectile to achieve a constant high speed. The velocities are measured by a set of two infrared emitters-detector pairs and a time counter, which is located at the end of the launch tube. The cutting speed can be controlled by adjusting the pressure of the air gun and the weight of projectile. By using a lightweight bakelite projectile and employing a maximum gas pressure ( $2 \mathrm{MPa}$ ), a maximum cutting speed of about $200 \mathrm{~m} / \mathrm{s}$ can be achieved. The bakelite projectile together with the tool has a weight of $0.83 \mathrm{~kg}$, and the resultant kinetic energy of the projectile-tool is large enough to consume cutting energy. At the end of the launch tube, two specimen holders aligned with the launch tube support two symmetrically

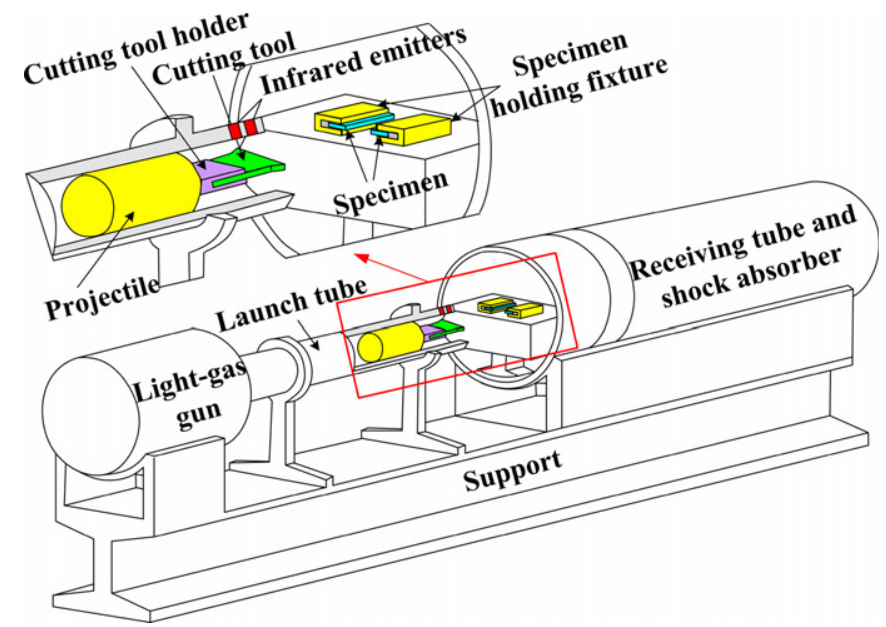

Fig. 1. The experimental system based on the light-gas-loading system.

fixed workpieces. The workpieces are placed in position inside the specimen holders, and the uncut chip thickness can be precisely controlled by adjusting the workpiece's position with a set of micrometer calipers. This is different from that of Sutter et al. [24,25], where the tool is fixed while the specimen moves with the projectile. The design of fixed specimen is convenient for the measurement of temperature and plastic strain in the workpeice during cutting in our later work. When the tool impacts the workpieces, the orthogonal machining occurs. In order to avoid undesirable decrease of the cutting speed due to the absorption of kinetic energy during the cutting process, optimal masses of the projectile was calculated so as to have a kinetic energy much larger than the cutting energy. Thus the cutting speed is nearly constant during the process and quasi-steady state cutting conditions are realized. After cutting, the receiving tube leads the projectile bearing the cutting tool into a shock absorber.

\subsection{Characteristic of the cutting tests}

Experiments have been performed on an AISI 1045 steel, with cutting speeds ranging from $30.8 \mathrm{~m} / \mathrm{s}$ to $67.3 \mathrm{~m} / \mathrm{s}$. The normalized AISI 1045 steel used in this study has a hardness of HV 178 and a static strength about $585 \mathrm{MPa}$. Specimens were machined into rectangles, and all tests were carried out with the same tool inserts, which are made of $\mathrm{W} 18 \mathrm{Cr} 4 \mathrm{~V}$ tool steel. The uncut chip thickness was obtained precisely for each specimen by the measurement of the height values before and after the test, respectively. To avoid the fracture of the tools at high impact velocities, small uncut chip thickness were considered. It should be noticed that, the uncut chip thickness used in this study $(0.05 \mathrm{~mm})$ is much smaller than that applied in Sutter et al. [24] $(0.3 \mathrm{~mm})$. This could lead to a higher transition cutting speed at which the saw-tooth chip comes out [14,26]. During cutting process, the cutting tool in relation to the workpiece is schematically presented in Fig. 2, and the corresponding cutting parameters marked in Fig. 2 are listed in Table 1. The width of the cutting insert is slightly larger than the width of the specimens to ensure the validity of the two-dimensional model assumption. New cutting inserts were used for each test to limit the tool wear. So in the present study, the tool wear effects can be neglected.

In this study, the width of specimen is $4 \mathrm{~mm}$, and cutting length is about $60 \mathrm{~mm}$. This means that higher energy must be consumed during cutting process. In order to achieve a stable cutting speed, a heavy aluminum projectile was used. The weight of the projectile and the tool is about $1.26 \mathrm{~kg}$. Moreover, for the sake of safety, we employed a relatively low pressure of gas, about 
$1 \mathrm{MPa}$. Thus, a maximum cutting speed was measured to be about $67.3 \mathrm{~m} / \mathrm{s}$. It must be pointed out that, the cutting speed $67.3 \mathrm{~m} / \mathrm{s}$ is extremely high for AISI 1045 steel. According to Schulz and Moriwaki [27], the lower and upper limit for high-speed machining of steels is about $5 \mathrm{~m} / \mathrm{s}$ and $40 \mathrm{~m} / \mathrm{s}$, respectively.

\section{Results and analysis}

\subsection{The cause for the saw-tooth chip formation during HSM AISI 1045 steel}

For microscopic observation, the chips have been collected and embedded into resin. The cross section was mechanically polished with aluminum oxide of $1 \mu \mathrm{m}$ particle size, and then etched with reagent Nital $2 \%$ for $5 \mathrm{~s}$. Microscopic observations were carried out to examine the influence of cutting speed on the chip formation. With increasing the cutting speed, chips change from continuous to saw-tooth-like, as shown in Fig. 3.

The microstructure of the uncut chip (the as-received material) presents a matrix composed predominantly of Widmanstatten ferrite and pearlite in clear and dark colors, respectively (Fig. 4a). The morphology of ferrite and pearlite is polygonal with many occurrences of slightly stretched and irregular grains, which can be characterized as a predominant acicular structure.

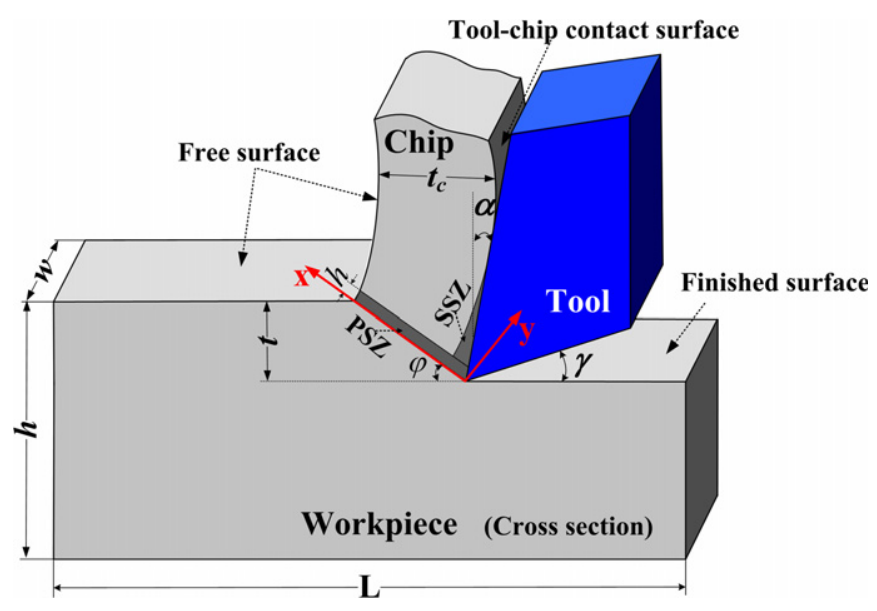

Fig. 2. The schematic diagram of the cutting process.
The microscopic observation shows that the metallographic structures in the as-received material are quite different form that in the chips, both for continuous chip formation (Fig. 4b) and for saw-tooth chip formation (Fig. 4c).

For velocities lower than $38.6 \mathrm{~m} / \mathrm{s}$, the chips are continuous. These chips are of constant thickness along its length. Fig. 4b shows the microstructure of the chip obtained at a cutting speed of $30.8 \mathrm{~m} / \mathrm{s}$. The microstructure observation shows that, the crystal particles in the chip have undergone a large deformation in the chip formation process. It can be noticed that, under this cutting speed the chip forms through relatively homogenous shear strain since the grains in the chip exhibit a markedly preferred orientation. This is in agreement with the homogenous shear assumption of the continuous chip, based on which the 'single-shear plane' orthogonal cutting models were proposed [28-31].

For cutting speed higher than $38.6 \mathrm{~m} / \mathrm{s}$, the chips become serrated. It can be seen that, this transition speed is indeed much higher than that reported in the work of Sutter et al. [24]. This could be primarily attributed to the smaller uncut chip thickness applied in this study [14,26]. When the velocity is up to $67.3 \mathrm{~m} / \mathrm{s}$, the shear localization becomes very sharp, and the adiabatic shear bands are widely observed between the saw-teeth, as shown in Fig. 4c. It can be easily found from the figure that the grains are dragged seriously in narrow layers, resulting in an extremely large shear deformation inside the shear bands. Moreover, from the magnified figure in Fig. 4c, the secondary shear zone (SSZ), which is resulted from the friction between tool and chip, also can be identified clearly by noting where the grains have been severely dragged in the opposite direction of chip flow. This is quite different from that of lower cutting speed, where the SSZ is obscure, and only a few gains which are closely adjacent to the tool-chip interface have been swept back, see Fig. 4b. This means that, increasing the cutting speed aggravates the tool-chip friction [32], which intensifies the material plastic deformation in the SSZ and hence raises the local temperature at the tool-chip contact surface [32,33]. It is also interesting to notice that, the crystal particles between the adjacent shear bands are stretched deviating from the shear direction. This indicates that a severe material flow occurs along the chip flow direction. As stated by Burns [21] and Jiang [22], the material flow leads to a mass transfer of heat, which takes heat away from the PSZ, and hence influences the temperature distribution in PSZ. Especially at sufficiently high cutting speeds, the transfer of heat in the cutting process could be dominated by the severe mass transfer of heat as well as the

Table 1

The cutting parameters.

\begin{tabular}{|c|c|c|c|c|c|c|}
\hline Workpiece width $w$ & Workpiece length $L$ & Workpiece height $h$ & Tool rake angle $\alpha$ & Tool clearance angle $\gamma$ & Uncut chip thickness $t$ & Tool edge radius \\
\hline $4 \mathrm{~mm}$ & $60 \mathrm{~mm}$ & $40 \mathrm{~mm}$ & $0^{\circ}$ & $7^{\circ}$ & $0.05 \mathrm{~mm}$ & $0.01 \mathrm{~mm}$ \\
\hline
\end{tabular}
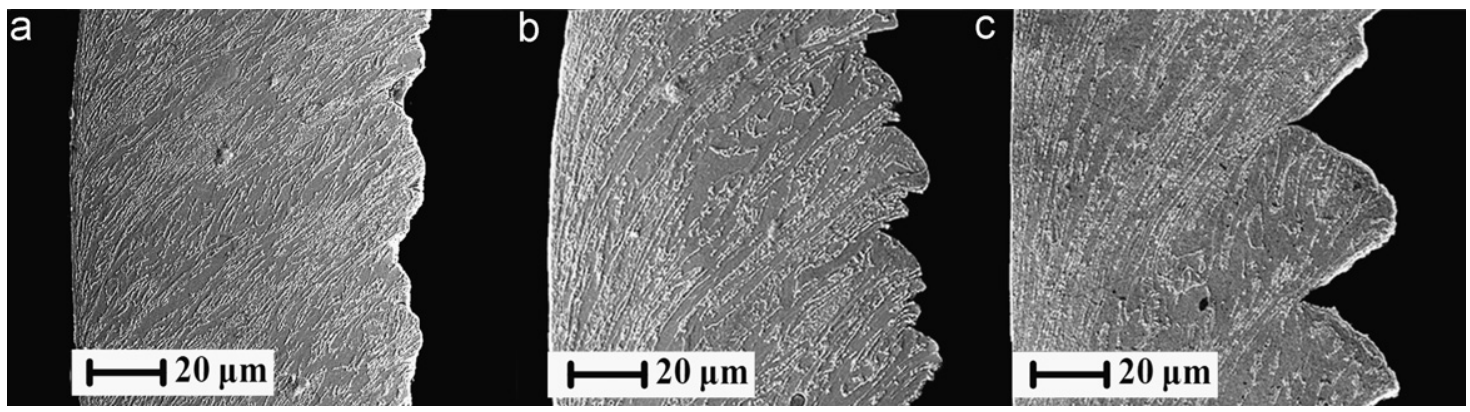

Fig. 3. The SEM microstructure of chip formation at cutting speed of: (a) $30.8 \mathrm{~m} / \mathrm{s}$, (b) $38.6 \mathrm{~m} / \mathrm{s}$, (c) $67.3 \mathrm{~m} / \mathrm{s}$. 
thermal diffusion. The effect of mass transfer of heat on the onset of saw-tooth chip formation will be discussed shortly.

In order to examine the influence of cutting speed on the structure of free surface (the free surface is schematically illustrated in Fig. 2), each surface of the uncut workpieces was polished, as shown in Fig. 4d. Examination of the free surface of the continuous chip reveals an irregular arranged lamellar structure, as shown in Fig. 4e. The shear surfaces (marked as ' $S$ ' in Fig. 4e) are occasionally visible, which can be characterized by the presence of tiny saw-teeth in the chip cross section, see Fig. $4 \mathrm{~b}$. Excluding the irregular occasional shear surfaces, the lamellae are relatively fine distributed. The mean lamellar width $d_{L}$ (as marked in Fig. 4e), or shear front spacing, is measured to lie in the range of $5 \sim 10 \mu \mathrm{m}$. Furthermore, it can be easily found from the microstructure of as-received material (Fig. 4a) that, the characterize grain size of the workpiece material is also in the range of $5 \sim 10 \mu \mathrm{m}$. Therefore, the lamellar width of the continuous chip seems to be very close to the micro-defects of the workpiece material, which is intrinsic and is largely independent of cutting speed $[14,22]$. It is worth noting that, the well-known "card model' [29] describes the cutting process as a sequential sliding of a 'deck of cards' (lamellae). According to this representation, not all atomic planes are active shear planes but only those associated with a structural defect (such as grain boundary). This gives rise to a process that the sequential sliding of the 'deck of cards' has a card thickness (lamellar width) that depends on the spacing of imperfections (grain size) [30]. It seems like that, the lamellar structure in the free surface of the continuous chip gives a support to this viewpoint. However it needs more systematic study.

For the saw-tooth segment, a fine shear front-lamellar structure is evident, as shown in Fig. 4f. The shear surfaces of each adjacent lamella are obviously visible. The shear displacement $L_{f}$ (as marked in Fig. 4f) is about $20 \sim 30 \mu \mathrm{m}$, which is in accordance with the segment tip spacing $L_{c}$ (as marked in Fig. 4c). Furthermore, carefully observation shows that, the primary lamella consists $2 \sim 4$ distinct or obscure secondary lamellae, the width of which is almost the same as that in the continuous chip (about $5 \sim 10 \mu \mathrm{m}$ ). The similarity between the free side of the continuous and saw-tooth chips suggest that, the formation of both continuous and saw-tooth chips can be attributed to shear deformation, which is homogeneous for continuous chips and periodic localized for saw-tooth chips, respectively. Moreover, as is well known, the dimple structure is typical of ductile fracture for the AISI 1045 steel. However, the dimple structure is not found on examination of the shear surface of the saw-tooth chips (see Fig. 4f). And no evidence of unstable crack is observed between the saw-teeth from the cross-section micrographs for all saw-tooth chips (see Fig. 4c). It should be noticed that, the AISI 1045 steel used in this study has a good ductility, and according to Autenrieth et al. [34] and Vaziri et al. [35], increasing strain rate and increasing temperature (both are caused by high cutting speed) act to enhance the fracture toughness of AISI 1045 steel. Thus the crack initiation/propagation is limited and shear localization is developed at high cutting speed. Therefore, as for AISI 1045 steel, it more reasonable to believe that the saw-tooth chip
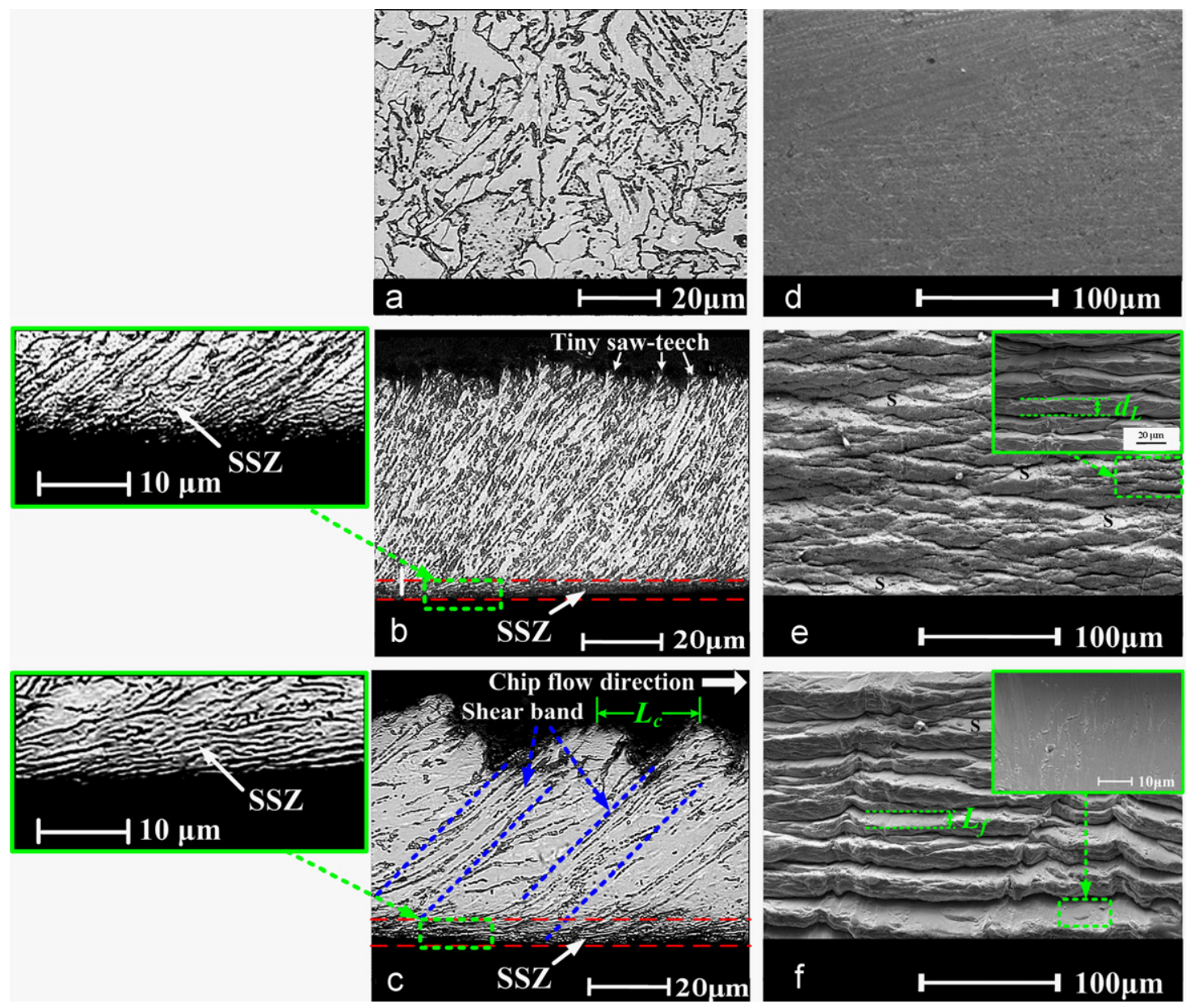

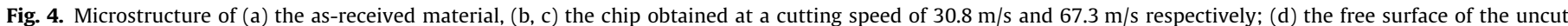
workpiece; (e, f) the free surface of chips obtained at cutting speed of $30.8 \mathrm{~m} / \mathrm{s}$ and $67.3 \mathrm{~m} / \mathrm{s}$ respectively (The free surface is schematically illustrated in Fig. 2 .). 
formation takes place due to the mechanism of catastrophic thermoplastic shear rather than periodic fracture initiation in the free surface of workpiece. It is also worth noting that, this fine lamellar structure is similar to that obtained in machining bulk metallic glasses (BMG), though the lamellar width in BMG is much smaller due to its distinct structural characteristic $[11,22]$. The lamellar chips of BMG were also proposed to result from a periodic shear-banding formation.

\subsection{Workpiece surface integrity and chip micro-hardness}

Fig. 5 shows the SEM microstructure of the machined surfaces obtained at the cutting speed of $30.8 \mathrm{~m} / \mathrm{s}$ and $67.3 \mathrm{~m} / \mathrm{s}$, respectively. The surface produced by low cutting speed machining shows heavy smearing and displays a great number of irregular feed marks embedded in the smoothed area (Fig. 5a). The surface produced at the velocity of $67.3 \mathrm{~m} / \mathrm{s}$ presents a smoother surface than the samples generated at the speed of $30.8 \mathrm{~m} / \mathrm{s}$, with less smearing, and more regularity regarding feed marks. For most of ductile materials, removal occurs at the ductile regime accompanied by a large amount of plastic flow [36]. The plastic deformation turns the finished surface to undesirables including worse roughness and larger residual stress. Higher cutting speed results in a shorter time for the plastic deformation to take place, thus, the plastic flow becomes limited, which results in a high quality of surface integrity [37]. Therefore, it can be concluded that, during HSM, increasing the cutting speed could reduce the plastic flow, and, hence, increase the smoothness of the machined surface.

We have also measured the micro-hardness of chips since it is an indication of both strain and temperature history. Vichers Hardness has been measured using a Tukon Micro-hardness tester and a load of $10 \mathrm{gf}$. The average mirco-hardness measurement results for the continuous chip and the two zones of the serrated chip are given in Table 2. The two zones of the serrated chip correspond to the region in the shear band subjected to high strains (HS zone) and the region out of the shear band subjected to low strains (LS zone). The measurement shows that, the mean hardness of the continuous chip is $336 \mathrm{HV}$, which is higher than that $(178 \mathrm{HV})$ of the workpiece material. And for the serrated chip, the mean hardness is $410 \mathrm{HV}$ in the HS zone and $241 \mathrm{HV}$ in the LS zone. It is worth noting that, the chip formation process is somewhat similar to the equal channel angular extrusion, which has been widely used as a severe plastic deformation (SPD) approach
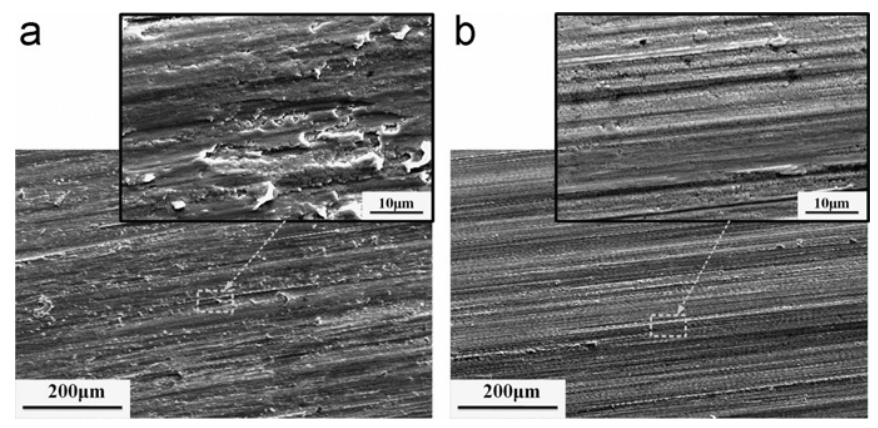

Fig. 5. SEM microstructures of the finished surfaces at cutting speed of (a) $30.8 \mathrm{~m} / \mathrm{s}$ and (b) $67.3 \mathrm{~m} / \mathrm{s}$.

Table 2

The Vichers hardness measurement results.

\begin{tabular}{llll}
\hline $\begin{array}{l}\text { Workpiece } \\
\text { material }\end{array}$ & $\begin{array}{l}\text { Continuous chip } \\
(30.8 \mathrm{~m} / \mathrm{s})\end{array}$ & $\begin{array}{l}\text { HS zone of serrated } \\
\text { chip }(67.3 \mathrm{~m} / \mathrm{s})\end{array}$ & $\begin{array}{l}\text { LS zone of serrated } \\
\text { chip }(67.3 \mathrm{~m} / \mathrm{s})\end{array}$ \\
\hline $178 \mathrm{HV}$ & $336 \mathrm{HV}$ & $410 \mathrm{HV}$ & $241 \mathrm{HV}$ \\
\hline
\end{tabular}

for achieving microstructure refinement in metals and alloys [38]. During HSM, the material undergoes severe plastic deformation in the primary shear zone. After the large strain plastic deformation, the microstructure refinement takes place. This reduces the grain size and the dislocation substructures in the chips, and hence increases the chip hardness [38,39]. Moreover, the differences in hardness values between the HS and LS zones of serrated chip and the continuous chip agree with the expectation that the hardness should increase with plastic strain [38].

\subsection{The influence of mass transfer of heat on the onset of saw-tooth} chip formation

As discussed above, the saw tooth chip formation could be attributed to repeated adiabatic shear banding. Thus the thermoplastic instability would occur within the PSZ during the machining of the present steel. In the following, we shall investigate the onset of saw-tooth chip formation by examining the instability of the PSZ.

The PSZ can be modeled as a planar layer infinitely extended in the shear direction $x$ and, with a finite height $h$ in the $y$ direction $[8,21,22]$, as sketched in Fig. 2. The constitutive law of material usually has the general form:

$\tau=f(\gamma, \dot{\gamma}, T)$

where $\tau$ is the shear stress, $\gamma$ shear strain, $\dot{\gamma}$ shear strain rate, and $T$ temperature.

The basic equations governing the thermo-mechanical deformation of PSZ can be written as

$\frac{\partial^{2} \tau}{\partial y^{2}}=\rho \frac{\partial^{2} \gamma}{\partial t^{2}}$

$\frac{\partial T}{\partial t}=\frac{\beta \tau}{\rho c} \frac{\partial \gamma}{\partial t}+\frac{K}{\rho c} \frac{\partial^{2} T}{\partial y^{2}}-V \sin \varphi \frac{\partial T}{\partial y}$

where (2) is the momentum equation, (3) temperature evolution equation. In these equations, $\rho$ is mass density, $c$ thermal capacity, $K$ thermal conductivity, $\beta$ the Taylor and Quinney coefficient, $V$ the cutting speed, and $\varphi$ is the primary shear angle. Eq. (3) states that there are three different physical processes that can alter the temperature in the PSZ: heat generation due to plastic working (the first term), diffusion and mass transfer of heat (the second and third terms, respectively). The temperature can be redistributed by the diffusion until it is spatially uniform. It is noted that the mass transfer of heat is due to the material moving outwards the PSZ (see Fig. 4c), which should be important in HSM process [21,22].

The shear banding formation is a result of instability of homogeneous deformation within the PSZ. We therefore first examine the homogeneous deformation that would provide some clues for understanding the resultant shear instability process. In the homogeneous case, the governing Eqs. (2) and (3) become

$\frac{d \gamma}{\partial t}=0$

$\frac{d T}{d t}=\frac{\beta \tau \dot{\gamma}}{\rho c}+\frac{4 K}{\rho c} \frac{T_{0}-T}{h^{2}}-\frac{T-T_{0}}{h /(V \sin \varphi)}$

Here, the heat flow only occurs on the boundary surfaces of the PSZ [21,22]. For the material behavior of the machined workpiece (AISI 1045 steel), a Johnson-Cook model is usually adopted $[40,41]$. Thus the Eq. (1) can be given as

$\tau=\frac{1}{\sqrt{3}}\left(A+B\left(\frac{\gamma}{\sqrt{3}}\right)^{n}\right)\left(1+C \ln \frac{\dot{\gamma}}{\dot{\gamma}_{0}}\right)\left(1-\frac{T-T_{0}}{T_{\text {melt }}-T_{0}}\right)$

where $\dot{\gamma}_{0}$ is the reference strain rate, $T$ the material temperature in PSZ, $T_{0}$ the room temperature, and $T_{\text {melt }}$ is the melting temperature, $A$ the initial yield stress, $B$ the hardening modulus, 
$n$ the work-hardening exponent, $C$ the strain rate dependency coefficient, and $m$ is the thermal softening coefficient. The Johnson-Cook parameter values and other mechanical properties used to describe the behavior of AISI 1045 workpiece are specified in Table 3 [40].

According to Eq. (4), the shear strain $\gamma$ increases linearly with time at the constant strain rate. In the present cutting case, the constant strain rate is related to the cutting speed by

$\dot{\gamma}=\frac{V}{h \cos \varphi}$

where the width of PSZ $h$ and the shear angle $\varphi$ are chose to be $10 \mu \mathrm{m}$ and $35^{\circ}$, respectively, in accordance with the experiment results (see Fig. $4 \mathrm{~b}$ and $\mathrm{c}$ ).

Thus, for a given cutting speed, the shear stress and temperature can be obtained by numerically integrating Eqs. (5)-(7). Based on this, the thermo-plastic deformation within the PSZ as well as the effect of mass transfer of heat can be obtained.

In order to examine the influence of mass transfer of heat on the thermo-plastic behavior within the PSZ, we purposely discuss three typical cases: (i) Adiabatic deformation, where the mass transfer of heat and diffusion terms in Eq. (5) vanish; (ii) Conventional deformation, where the diffusion is considered and the mass

Table 3

Mechanical properties and parameters for AISI 1045 steel.

\begin{tabular}{lll}
\hline Properties and parameters & Notation & Value \\
\hline Density & $\rho$ & $7800 \mathrm{~kg} \mathrm{~m}^{-3}$ \\
Thermal conductivity & $K$ & $38 \mathrm{~W} \mathrm{~m}^{-1} \mathrm{~K}^{-1}$ \\
Specific heat & $c$ & $420 \mathrm{~J} \mathrm{~kg}^{-1} \mathrm{~K}^{-1}$ \\
Tayor-Quinney coefficeient & $\beta$ & 0.9 \\
Initial yield stress & $A$ & $553 \mathrm{MPa}$ \\
Hardening modulus & $B$ & $600 \mathrm{MPa}$ \\
Strain rate dependency coefficient & $C$ & 0.0134 \\
Work-hardening exponent & $n$ & 0.234 \\
Thermal softening coefficient & $m$ & 1 \\
The reference stain rate & $\dot{\gamma}_{0}$ & $1 \mathrm{~s}$ \\
Room temperature & $T_{0}$ & $300 \mathrm{~K}$ \\
Melting temperature & $T_{\text {melt }}$ & $1733 \mathrm{~K}$ \\
\hline
\end{tabular}

transfer of heat term in Eq. (5) vanishes; (iii) Coupling deformation, during which the diffusion and mass transfer of heat are considered simultaneously. Fig. 6 shows the shear stress versus shear strain at different cutting speeds for these three typical deformations. For the coupling deformation, the strain hardening takes place over the whole deformation process when the cutting speed is lower than $30 \mathrm{~m} / \mathrm{s}$. Once the cutting speed is up to $40 \mathrm{~m} / \mathrm{s}$, the plastic yielding occurs. After the peak stress, there is a continuing strain softening, resulting in shear banding [12,42], and hence the saw-tooth chip forms. This agrees well with the experimental result, where the chip formation changes from continuous to saw-tooth-like at about $38.6 \mathrm{~m} / \mathrm{s}$ (see Fig. 3). As for the adiabatic and conventional deformation, the plastic flow exhibits some different features. First, for a given cutting speed, the plastic yielding occurs earlier, and the peak stress is lower than the coupling one, implying the coupling activation energy softening the material be greater than that in the adiabatic or conventional case. It states clearly that the mass transfer of heat makes the strain softening more difficultly to take place, which leads to a stabilization of the PSZ. Second, the plastic yielding could occur at any cutting speed for adiabatic condition, and the strain softening vanishes only at the cutting speed lower than $10 \mathrm{~m} / \mathrm{s}$ for conventional deformation. The plastic yielding takes place at higher cutting speed for coupling deformation also demonstrates that the mass transfer of heat retards the initiation of instability.

Fig. 7 gives the temperature-shear strain curves for different cutting speeds. For each cutting speed, the coupling deformation temperature is lower than the adiabatic and conventional one. This implies that the mass transfer of heat restricts the temperature rise, which weakens the thermal softening effect in the PSZ and hence retards the occurrence of the plastic yielding. This is in accordance with the tendency of the shear stress evolution. Moreover, it also can be found from Fig. 7 that, for coupling deformation, the temperature rise is promoted with increase in cutting speed. Therefore, increasing the cutting speed enhances the thermal softening, and hence facilitates the shear banding formation. Consequently, when the cutting speed attains the certain critical value, the thermal softening caused by plastic

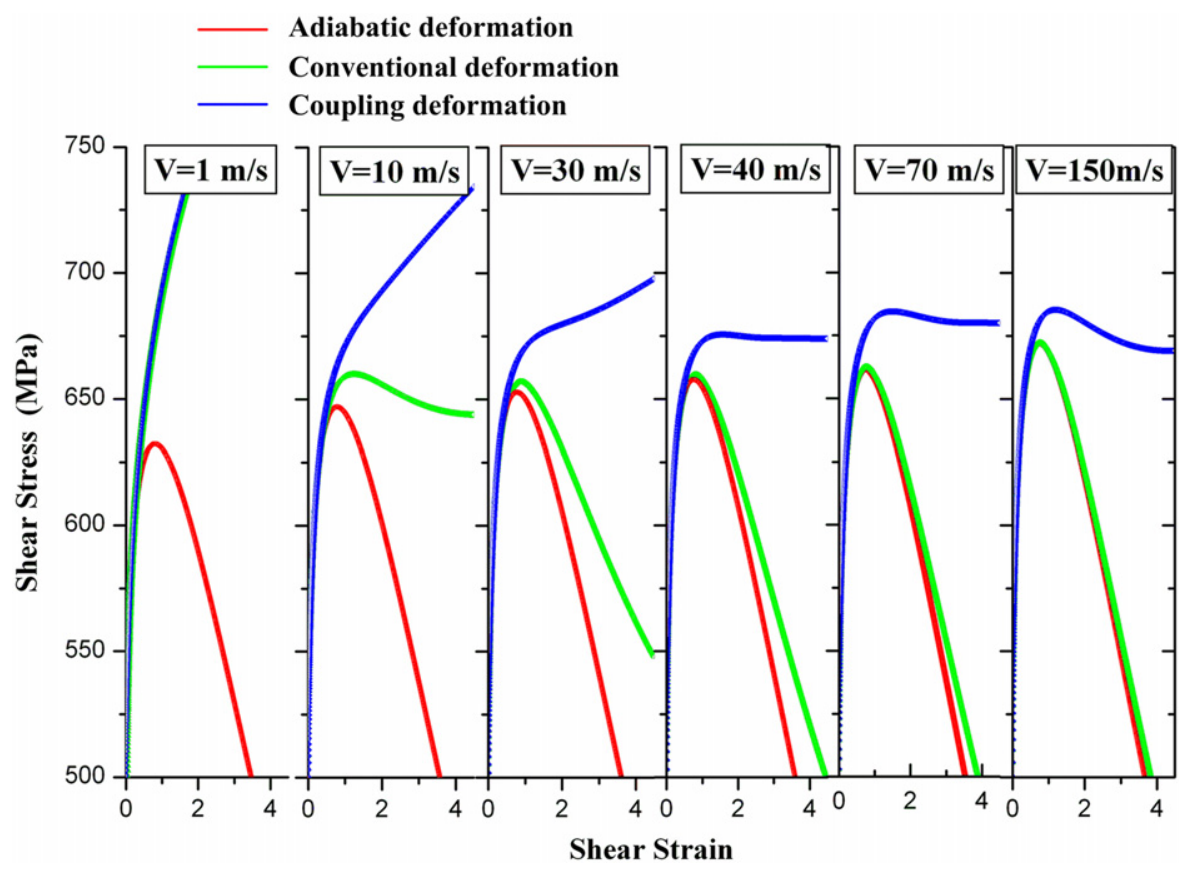

Fig. 6. The shear stress versus shear strain for various cutting speeds. 


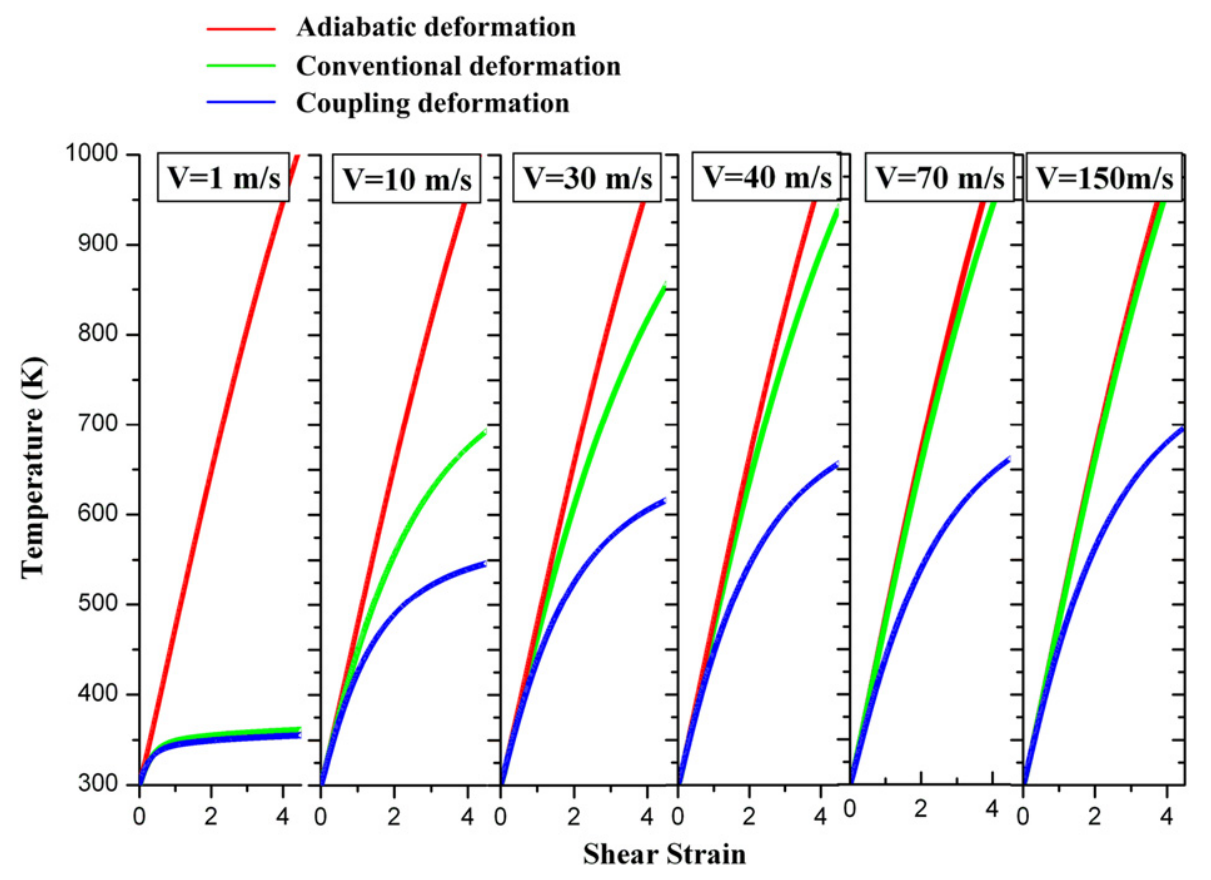

Fig. 7. The temperature versus shear strain for various cutting speeds.

work overcomes the strain hardening of the material, thus the plastic yielding occurs followed by a precipitous drop in stress, and the shear band forms inside the PSZ.

In addition, it can be noticed from Figs. 6 and 7 that, the stressstrain curve and temperature-stain curve of the conventional deformation are far away from the curve of adiabatic deformation but close to the coupling one at low cutting speed. So when the cutting action is slow, the thermal diffusion effect is prominent. Thus most of the heat generated in the PSZ is conducted into the workpiece, making the finished surface much hotter. However, with the cutting speed increasing, the curve of conventional deformation changes to be close to the adiabatic one but far away from the coupling one. This means that, increasing the cutting speed weakens the thermal diffusion but enhances the mass transfer, which carries the heat away with the chip flow. Fig.8 shows the variation of the fraction of the heat source conducted into the workpiece material $\left(F_{\text {work }}\right)$ with the cutting speed. The heat partitions were worked out from the temperature-shear strain curves for a given shear strain. And the average shear strain was set to be 2.13 according to Merchant [28]. It can be seen from Fig. 8 that, the calculated heat partitions are in good agreement with Leone [43] and Loewen and Shaw [44], especially for higher cutting speeds. This figure states clearly that the higher the cutting speed the less the fraction of the heat source conducted into the workmaterial. As the cutting speed increases, there is less time available for the heat to conduct into the workpiece, and hence the machined surface temperature decreases. Thus, it seems like that the Salomon's theory does hold if the 'cutting temperature' is defined as the machined surface temperature $[5,45,46]$. On the other hand, the faster the cutting action the more effectively the heat carries away by the chip flow $[43,44]$, and thus more heat conducts into the cutter through the tool-chip contact surface. Moreover, as mentioned in Section 3.1, increasing the cutting speed intensifies the tool-chip friction, raising the local temperature at the tool-chip contact. Consequently, higher tool-chip interface temperature is generated as the cutting speed increases. So, when the 'cutting temperature' is defined as the tool-chip interface temperature, the Salomon's theory is seemingly unavailable, see the work of Komanduri [5], Sutter and Ranc [25] and McGee [47].
Furthermore, the shear banding instability can be analyzed via seeking an inhomogeneous deformation solution with respect to small perturbations on the homogeneous solution $[42,48,49]$. We impose a perturbation $\left(\tau^{\prime}, \gamma^{\prime}, T^{\prime}\right)$ on the homogeneous solution $\left(\tau_{0}, \gamma_{0}, T_{0}\right)$ of the problems (1)-(3), such that

$$
\left.\begin{array}{l}
\tau=\tau_{0}+\tau^{\prime} \\
\gamma=\gamma_{0}+\gamma^{\prime} \\
T=T_{0}+T^{\prime}
\end{array}\right\}
$$

The perturbation has the following form:

$$
\left.\begin{array}{l}
\tau^{\prime}=\tau_{*} e^{\alpha t+i k y} \\
\gamma^{\prime}=\gamma_{*} e^{\alpha t+i k y} \\
T^{\prime}=T_{*} e^{\alpha t+i k y}
\end{array}\right\}
$$

where $\left(\tau_{*}, \gamma_{*}, T_{*}\right)$ are small constants that characterize the initial magnitude of the perturbation, $\alpha$ the initial growth rate of the perturbation, and $k$ the wave number. If $\alpha$ has a positive real root, it implies that instability is possible, and the saw-tooth chip formation is formed.

Inserting Eqs. (8) and (9) into Eqs. (1)-(3) and only considering the first order terms of the perturbations, we obtain the spectral equation about the perturbation growth rate

$$
\begin{aligned}
& \rho^{2} c \alpha^{3}+\rho\left(\beta \dot{\gamma}_{0} P_{0}+\left(K+c R_{0}\right) k^{2}+\rho c V_{f} k i\right) \alpha^{2} \\
& +\left(K R_{0} k^{2}+\rho c Q_{0}-\beta \tau_{0} P_{0}+\rho c k R_{0} V_{f} i\right) k^{2} \alpha+K Q_{0} k^{4}+\rho c Q_{0} V_{f} k^{3} i=0
\end{aligned}
$$

where $Q_{0}$ is the strain hardening of the material, $R_{0}$ strain-rate hardening, and $P_{0}$ its thermal softening.

Rearranging, using the dimensionless variables

$\left.\begin{array}{l}\hat{\alpha}=\frac{K \alpha}{c Q_{0}}, \hat{k}^{2}=\frac{K^{2}}{\rho c^{2} Q_{0}} k^{2}, A=\frac{c R_{0}}{K}, B=\frac{\beta \tau_{0} P_{0}}{\rho c Q_{0}}, \\ C=\frac{\beta K P_{0} \dot{\gamma}_{0}}{\rho c^{2} Q_{0}}, D=V \sin \phi \sqrt{\frac{\rho}{Q_{0}}} \hat{k} i\end{array}\right\}$

reduces the spectral equation to the form

$\hat{\alpha}^{3}+\left(C+(1+A) \hat{k}^{2}+D\right) \hat{\alpha}^{2}+\left(A \hat{k}^{2}+1-B+A D\right) \hat{k}^{2} \hat{\alpha}+\hat{k}^{4}+D \hat{k}^{2}=0$ 


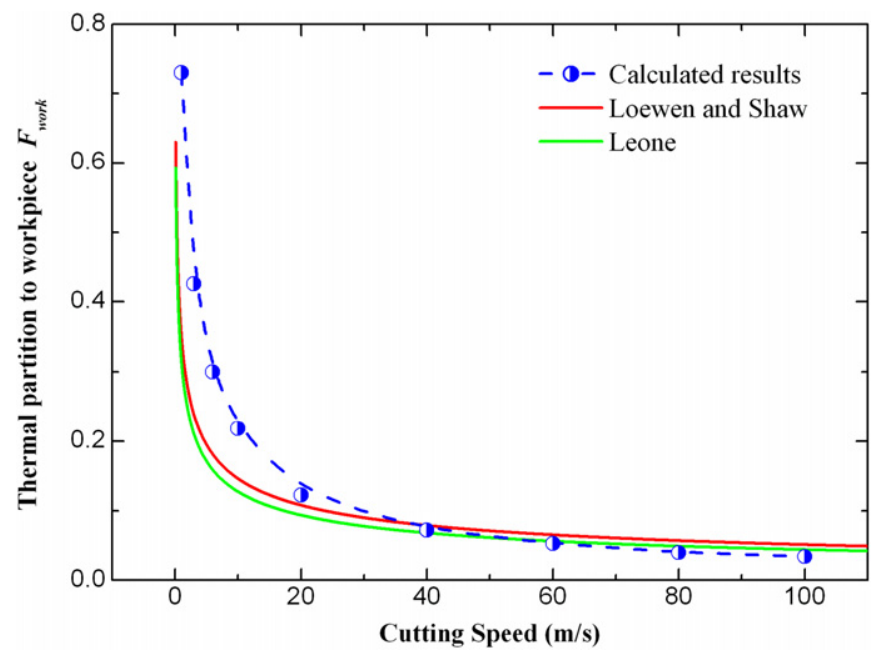

Fig. 8. The variation of the heat partition conducted into workmaterial with cutting speed. The heat partition conducted into workmaterial was given as $F_{\text {work }}=1 /\left(1.13\left(t / t_{c}\right) \sqrt{\rho c V t / 2 K \sin \varphi}\right)$ by Leone [43] and $F_{\text {work }}=1-1 /(1+$ $1.328 \sqrt{K / \rho c V t_{c}}$ ) by Loewen and Shaw [44], where $t_{c}$ is the chip thickness.

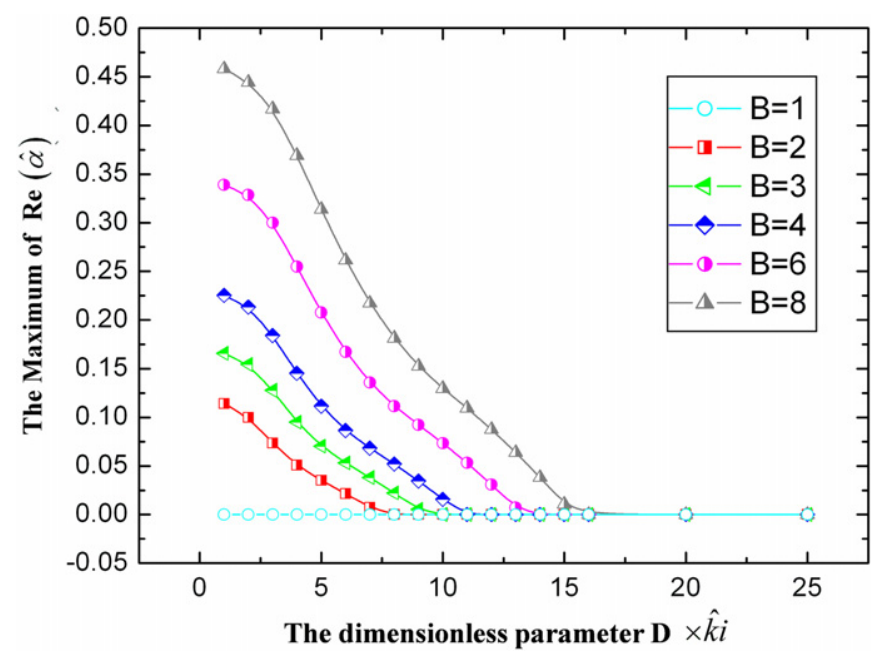

Fig. 9. The maximum of the real part of $\tilde{\alpha}$ plotted with the convection parameter $D$ for different $B$.

Among these dimensionless variables marked in Eq. (11), $B$ characterizes the competition between the thermal softening and strain hardening, $D$ reflects the magnitude of mass transfer of heat. It is clearly seen from Eq. (12) that if the effect of mass transfer of heat is neglected, i.e. $D=0$, the problem is reduced to the conventional thermoplastic shearing investigated by Bai [48], and the instability condition $B>1$ is derived, which means that when the thermal softening caused by plastic work overcomes the work hardening of the material the instability occurs.

For each fixed dimensionless parameter $D$, the real parts of the roots of Eq. (12) are functions of the wave number. If instability occurs, it must occur at a special set of wave numbers for which the corresponding real part of the growth rate $(\operatorname{Re}(\alpha))$ takes a peak maximum value. To seek the dominant instability mode, the maximum value of $\operatorname{Re}(\tilde{\alpha})(\operatorname{Max} \cdot \operatorname{Re}(\tilde{\alpha}))$ should be determined by drawing the $\operatorname{Re}(\hat{\alpha}) V s \hat{k}$ curves. Thus the influence of mass transfer of heat on the onset of adiabatic shear also can be obtained.

In Fig. 9, the $(\operatorname{Max} \cdot \operatorname{Re}(\tilde{\alpha}))$ are plotted as a function of the dimensionless parameter $D$ for various $B$, where $A$ and $C$ are chose to be 10 and $10^{-4}$ for high-speed cutting, respectively. For a fixed $D$, increasing $B$ increases the $\operatorname{Max} \cdot \operatorname{Re}(\tilde{\alpha})$, hence accelerates the instability and promotes the formation of saw-tooth chip. This is consistent with that in the simple shear case. Furthermore, for a fixed dimensionless parameter $B$, the Max. $\operatorname{Re}(\tilde{\alpha})$ decreases with increasing $D$. The trend shows that the mass transfer of heat retards the perturbation growth, and thus hinders the formation of saw-tooth chip.

As shown in Figs. 6 and 7, increasing the cutting speed would facilitate the shear instability. Consequently, when the cutting speed attains a certain critical value, the thermo-mechanical deformation of PSZ could meet the instability condition governed by Eq. (12), hence the shear band forms in the PSZ. The initiation and propagation of this shear band will decrease the shear stress within the PSZ due to energy dissipation. At this time, the heat production ceases, and the PSZ is cooled by diffusion and mass transfer of heat. Soon, however, as the tool keeps on moving, new uncut chip material passes through the PSZ for another buildup in stress and temperature to occur. Thus the cutting cycle repeats itself, and the reaped shear banding forms, which results in the saw tooth chip formation (see Fig. 4c).

\section{Conclusions}

An experimental device, providing HSM at a cutting speed up to $200 \mathrm{~m} / \mathrm{s}$, was developed based on a light-gas gun. The HSM experiments for an AISI 1045 steel were carried out with velocities ranging from $30.8 \mathrm{~m} / \mathrm{s}$ to $67.3 \mathrm{~m} / \mathrm{s}$. A transition from continuous to saw-tooth chip formation was observed within the range of cutting speeds employed. The microstructure observations indicate that the repeated catastrophic thermoplastic shear-instability, rather than the periodic cracking, results in the saw-tooth chip formation process. The thermo-plastic instability behavior in the PSZ is further investigated, which reveals that the mass transfer of heat retards the instability and thus hinders the formation of saw-tooth chip. In addition, the results also demonstrate that, increasing the cutting speed weakens the thermal diffusion and enhances the mass transfer. Therefore, increasing the cutting seed would lead to a decrease of the finished surface temperature and an increase of the tool-chip contact temperature.

\section{Acknowledgments}

This work has been supported by the Nature Science Foundation of China (Grants nos.11132011, 10725211, 11021262 and 11002144), the National Basic Research Program of China (Grant no: 2009CB724401), and the National Natural Science Foundation of China-NSAF. Grant no: 10976100.

\section{References}

[1] P. Chevrier, A Tidu, B. Bolle, P. Cezard, J.P. Tinnes, Investigation of surface integrity in high speed end milling of a low alloyed steel, International Journal of Machine Tools and Manufacture 43 (2003) 1135-1142.

[2] N.A. Abukhshim, P.T. Mativenga, M.A. Sheikh, Heat generation and temperature prediction in metal cutting: a review and implications for high speed machining, International Journal of Machine Tools and Manufacture 46 (2006) 782-800

[3] C.J. Salomon, Process for the Machining of Metals or Similarly Acting Materials When Being Worked by Cutting Tools, German Patent, Number 523594, 1931-04

[4] R. Komanduri, High-speed machining, Mechanical Engineering (1985) 64-76

[5] J.M. Longbottom, J.D. Lanham, A review of research related to Salomon's hypothesis on cutting speed and temperatures, International Journal of Machine Tools and Manufacture 46 (2006) 1740-1747.

[6] R. Komanduri, Shear-localization machining, Journal of Metals 36 (1984) 59.

[7] M.C. Shaw, A. Vyas, Chip formation in the machining of hardened steel, Annals of the CIRP 42 (1) (1993) 29-33.

[8] Molinari, C. Musquar, G. Sutter, Adiabatic shear banding in high speed machining of Ti-6AL-4 V: experiments and modeling, International Journal of Plasticity 18 (2002) 443-459. 
[9] G. Sutter, Chip geometries during high-speed machining for orthogonal cutting condition, International Journal of Machine Tools and Manufacture 45 (2005) 719-726.

[10] M.A. Davies, Y. Chou, C.J. Evans, On chip morphology, tool wear and cutting mechanics in finish hard turning, Annals of the CIRP 45 (1) (1996) 77-82.

[11] M. Bakkal, A.J. Shih, R.O. Scattergood, Chip formation, cutting forces, and tool wear in turning of Zr-based bulk metallic glass, International Journal of Machine Tools and Manufacture 44 (2004) 915-925.

[12] R.F. Recht, Catastrophic thermoplastic shear, Transaction of ASME 86 (1964) 186-193.

[13] M.A. Davies, T.J. Burns, C.J. Evans, On the dynamics of chip formation in the machining of hard metals, Annals of the CIRP 46 (1) (1997) 25-30.

[14] J. Barry, G. Byrne, The mechanisms of chip formation in machining hardened steel, Journal of Manufacturing Science and Engineering, Transactions of ASME 124 (2002) 528-535.

[15] K. Nakayama, M. Arai, T. Kada, Machining characteristics of hard materials, Annals of the CIRP 37 (1) (1988) 89-92.

[16] M.A. Elbestawi, A.K. Srivastava, T.I. El-Wardany, A model for chip formation during machining of hardened steel, Annals of the CIRP 45 (1) (1996) 71-76.

[17] Vyas, M.C. Shaw, Mechanics of saw-tooth chip formation in metal cutting Journal of Manufacturing Science and Engineering, Transactions of ASME 121 (1999) 163-172.

[18] V.P. Astakhov, Geometry of Single-Point Turning Tools and Drills, Springer London Ltd., London, 2010.

[19] V.P. Astakhov, Metal Cutting Mechanics, USA CRC Press, Boca Raton, 1998.

[20] J.Y. Sheikh-Ahmad, V. Quarless, J.A. Bailey, On the role of microcracks on flow instability in low speed machining of CP titanium, Machining Science and Technology 8 (2004) 415-430.

[21] T.J. Burns, M.A. Davies, On repeated adiabatic shear band formation during high-speed machining, International Journal of Plasticity 18 (2002) 487-506.

[22] M.Q. Jiang, L.H. Dai, Formation mechanism of lamellar chips during machining of bulk metallic glass, Acta Materialia 57 (2009) 2730-2738.

[23] R.V. Kazban, K.M. Vernaza-Peñfa, J.J. Mason, Measurements of forces and temperature fields in high-speed machining of 6061-T6 aluminum alloy, Experimental Mechanics 48 (2008) 307-317.

[24] G. Sutter, L. Faure, A. Molinari, A. Delime, D. Dudzinski, Experimental analysis of the cutting process and chip formation at high speed machining, Journal De Physique IV 7 (1997) 33-38.

[25] G. Sutter, N. Ranc, Temperature fields in a chip during high-speed orthogonal cutting: an experimental investigation, International Journal of Machine Tools and Manufacture 47 (2007) 1507-1517.

[26] L. Deshayes, T. Mabrouki, R. Ivester, J.-F. Rigal, Serrated chip morphology and comparison with finite element simulations, in: Proceedings of the 2004 ASME International Mechanical Engineering Congress and Exposition, Anaheim, California USA, 2004

[27] H Schulz, T. Moriwaki, High-speed machining, Annals of CIRP 41 (2) (1992) 637-642.

[28] M.E. Merchant, Mechanics of the metal cutting process I: orthogonal cutting and the type 2 chip, Journal of Applied Physics 16 (1945) 267-275.

[29] V. Piispanen, Theory of formation of metal chips, Journal of Applied Physics 19 (1948) 876-881.

[30] M.C. Shaw, Metal Cutting Principles, 2nd ed., Oxford University Press, Oxford, 2005.
[31] A.G. Atkins, Modelling metal cutting using modern ductile fracture mechanics quantitative explanations for some long standing problems, International Journal of Mechanical Sciences 45 (2003) 373-396.

[32] T. özel, T. Altan, Determination of workpiece flow stress and friction at the chip-tool contact for high-speed cutting, International Journal of Machine Tools and Manufacture 40 (2000) 133-152.

[33] R. Komanduri, Z.B. Hou, Thermal modeling of the metal cutting process Part II: temperature rise distribution due to frictional heat source at the tool-chip interface, International Journal of Mechanical Sciences 43 (2001) 57-88.

[34] H. Autenrieth, V. Schulze, N. Herzig, L.W. Meyer, Ductile failure model for the description of AISI 1045 behavior under different loading conditions, Mechanics of time-dependant materials 13 (2009) 215-231.

[35] M.R. Vaziri, M. Salimi, M. Mashayekhi, A new calibration method for ductile fracture models as chip separation criteria in machining, Simulation Modelling Practice and Theory 18 (2010) 1286-1296.

[36] J. Shimizu, L.B. Zhou, H. Eda, Simulation and experimental analysis of super high-speed grinding of ductile material, Journal of Materials Processing Technology 129 (2002) 19-24.

[37] B. Shiari, R.E. Miller, D.D. Klug, Multiscale simulation of material removal processes at the nanoscale, Journal of the Mechanics and Physics of Solids 55 (2007) 2384-2405.

[38] S. Swaminathan, M.R. Shankar, S. Lee, Large strain deformation and ultra-fine grained materials by machining, Materials Science and Engineering A 410411 (2005) 358-363.

[39] J. Limido, C. Espinos, M. Salaün, J.L. Lacome, SPH method applied to high speed cutting modeling, International Journal of Mechanical Sciences 49 (2007) 898-908

[40] S.P.F.C. Jaspers, J.H. Dautzenberg, Material behavior in conditions similar to metal cutting: flow stress in the primary shear zone, Journal of Materials Processing Technology 122 (2002) 322-330.

[41] M. Mohammadpour, M.R. Razfar, R. Jalili-Saffar, Numerical investigating the effect of machining parameters on residual stresses in orthogonal cutting, Simulation Modelling Practice and Theory 18 (2010) 378-389.

[42] M.Q. Jiang, L.H. Dai, On the origin of shear banding instability in metallic glasses, Journal of the Mechanics and Physics of Solids 57 (2009) 1267-1292.

[43] W.C. Leone, Distribution of shear-zone heat in metal cutting, Transactions of ASME 76 (1954) 121-125.

[44] E.G. Loewen, M.C. Shaw, On the analysis of cutting tool temperatures, Transactions of ASME 71 (1954) 217-231.

[45] D.J. Richardson, M.A. Keavey, F. Dailami, Modelling of cutting induced workpiece temperatures for dry milling, International Journal of Machine Tools and Manufacture 46 (2006) 1139-1145.

[46] D. O'Sullivan, M. Cotterell, Workpiece temperature measurement in machining, Proceedings of the Institute of Mechanical Engineers, Part $\mathrm{H}$ : Journal of Engineering in Medicine 216 (Part B) (2002) 135-139.

[47] F.J. McGee, An Assessment of High-Speed Machining, Technical Paper, Society of Manufacturing Engineers, MR, 1978, pp. 78-648.

[48] Y.L. Bai, Thermo-plastic instability in simple shear, Journal of the Mechanics and Physics of Solids 30 (4) (1982) 195-207.

[49] A. Molinari, Collective behavior and spacing of adiabatic shear bands, Journal of the Mechanics and Physics of Solids 45 (1997) 1551-1575. 